\title{
PREDICTIVE VALUE OF S-100 $\beta$ AND NEURON-SPECIFIC ENOLASE SERUM LEVELS FOR ADVERSE NEUROLOGIC OUTCOME AFTER CARDIAC SURGERY
}

Dimitrios Georgiadis, $\mathrm{MD}^{\mathrm{a}}$

Anja Berger ${ }^{\mathrm{a}}$

Ellen Kowatschev ${ }^{\mathrm{a}}$

Christine Lautenschläger, $\mathrm{PhD}^{\mathrm{b}}$

Angelika Börner, $\mathrm{PhD}^{\mathrm{c}}$

Alfred Lindner, MD

Wilhelm Schulte-Mattler, MD ${ }^{\mathrm{a}}$

Hans-Reinhard Zerkowski, MD ${ }^{\mathrm{d}}$

Stephan Zierz, MD

Thomas Deufel, $\mathrm{MD}^{\mathrm{c}}$
Objectives: The aim of this study was to evaluate the time course of $\mathrm{S}$ $100 \beta$ and neuron-specific enolase serum levels after cardiac surgery and their clinical relevance in predicting postoperative adverse neurologic outcomes; the 2 proteins are only released in peripheral blood in association with nervous system lesions. Methods: We neurologically assessed 190 consecutive patients undergoing elective cardiac operations for coronary artery bypass $(n=147)$, valve replacement $(n=29)$, or both $(n$ =14), before as well as after the operation. Postoperative outcome was classified as type I (uncomplicated), type II (confusion, agitation, disorientation, or epileptic seizures), or type III (stroke, stupor, or coma). Levels of S-100 $\beta$ and neuron-specific enolase were evaluated in venous blood samples drawn preoperatively and then daily in the first 5 postoperative days. Results: Levels of S-100 $\beta$ and neuron-specific enolase differed significantly among the 3 groups (type III > type II > type I) throughout the postoperative period and had a diagnostic specificity and specificity of $89 \%$ and $79 \%$, respectively, in identifying patients with type III outcome. S-100 $\beta$ (but not neuron-specific enolase) levels were identified as significant independent predictors for type II and III outcomes (odds ratio 16.2, $P<.0004)$. The same was true for duration of cardiopulmonary bypass (odds ratio $1.02, P<.006)$. Conclusions: Serum levels of S-100 $\beta$ are reliable markers for adverse neurologic outcomes after cardiac surgery. (J Thorac Cardiovasc Surg 2000;119:138-147)
$\mathrm{D}$ espite substantial methodologic improvements over the past decades, cardiac surgery with extracorporeal circulation remains a hazard to the brain. Incidences of postoperative stroke and adverse cerebral outcomes were recently reported as $2 \%{ }^{1}$ and $6.1 \%,{ }^{2}$ respectively; the prevalence of postoperative neuropsychologic deficit thereby is far higher, ${ }^{3-5}$ reaching values of $79 \%{ }^{3}$ in single studies.

S-100 is an acidic calcium-binding protein, with a molecular weight of $21 \mathrm{kDa}$ and a biologic half-life of

From the University Departments of Neurology, ${ }^{a}$ Cardio-Thoracic Surgery, ${ }^{\mathrm{d}}$ and Medical Statistics and Epidemiology, ${ }^{\mathrm{b}}$ Halle/Saale, and of Clinical Chemistry and Laboratory Diagnostics, ${ }^{\mathrm{c}}$ Jena, Germany.

Received for publication Feb 26, 1999; revisions requested April 30, 1999; revisions received Sept 10, 1999; accepted for publication Sept 16, 1999.

Address for reprints: D. Georgiadis, MD, Department of Neurology, Martin-Luther-University at Halle-Wittenberg, Ernst Grube Str 40, 06097 Halle/Saale, Germany (E-mail: dimitrios.georgiadis@medizin.uni-halle.de).

Copyright $\odot 2000$ by Mosby, Inc.

$0022-5223 / 2000 \$ 12.00+0 \quad \mathbf{1 2 / 1 / 1 0 3 0 1 5}$ approximately 2 hours. ${ }^{6}$ This protein consists of 2 subunits: $\mathrm{S}-100 \alpha \alpha$ is predominantly found in the heart, kidney, and striated muscles, $S-100 \alpha \beta$ in glial cells, and $\mathrm{S}-100 \beta \beta$ in astrocytes and Schwann cells. Thus the $\beta$ subunit of S-100 is specific for neuronal tissue. Neuronspecific enolase (NSE) has a molecular weight of 78 $\mathrm{kDa}$ and is mainly located in the cytoplasm of endocrine tissues and axonal processes. ${ }^{7}$ Release of both proteins into peripheral blood suggests neuronal injury changing both cell membrane integrity and permeability of the blood-brain barrier. To date, elevation of S-100 $\beta$ and/or NSE in peripheral blood has been reported in patients with a variety of cerebral lesions, including head injury, ${ }^{8,9}$ multiple sclerosis, ${ }^{10}$ status epilepticus, ${ }^{11,12}$ brain tumors, ${ }^{13}$ and stroke, ${ }^{14-18}$ as well as after circulatory arrest ${ }^{19}$ and cardiac operations. ${ }^{20-24}$ Several of the above reports; suggested a clinical relevance of both proteins in predicting size of cerebral lesions and/or functional outcome. , $9,14-17,23-25^{-1}$

We undertook this study to evaluate the clinical relevance of S-100 $\beta$ and NSE serum levels in patients undergoing elective cardiac operations. Additionally, the time course of potential changes in postoperative 
levels of both proteins was examined to evaluate the sampling time associated with the best predictive value for adverse neurologic outcomes.

\section{Patients and methods}

Patients. A total of 190 consecutive patients, 131 men and 59 women, aged $63 \pm 1$ years (mean \pm standard error), undergoing elective cardiac surgery for coronary artery bypass grafting (CABG, $n=147)$, valve replacement $(n=29)$, or both $(n=14)$, were enrolled in this study after informed consent had been obtained.

The presence of peripheral vascular disease, diabetes mellitus, or arterial hypertension was documented in all cases. Left ventricular ejection fraction was evaluated during transthoracic echocardiography. Preoperative neurologic assessment included detailed clinical examination and screening of the brain-supplying arteries by means of extracranial continuous wave Doppler $(n=165)$ and/or duplex studies $(n=47)$. Carotid disease was classified as mild (stenosis $<50 \%$ ), moderate (stenosis between $50 \%$ and $69 \%$ ), severe (stenosis between $70 \%$ and $99 \%$ ), or occlusion. In addition, duration of cardiopulmonary bypass (CPB), reperfusion, and total duration of the operative procedure (defined as time between skin incision and skin closure) were documented.

Neurologic assessment. For the purposes of the present study, all patients were neurologically assessed before the operation as well as on the fifth postoperative day. Patients referred to the neurologic service because of acute onset of neurologic symptoms were additionally evaluated on the day of referral and on subsequent occasions depending on their clinical course. Outcome was classified as type I (uncomplicated), type II (confusion, agitation, disorientation, or epileptic seizures), or type III (stroke, stupor, or coma). Patients with types II and III outcomes were neurologically reassessed before discharge and, in patients with persisting deficit, also in the fourth postoperative week. Cranial computed tomography (CCT) was routinely performed in all patients with type III and in selected patients with type II outcomes on the second postoperative day.

S-100 $\beta$ and NSE evaluation. Venous blood was drawn before the operation and then daily in the first 5 postoperative days, immediately centrifuged at $4000 \mathrm{~g}$ for 10 minutes, and stored at $-30^{\circ} \mathrm{C}$ until batch evaluation. Serum S-100 $\beta$ and NSE levels were measured by commercially available, monoclonal, 2-site immunoluminometric assays (LIA-mat and Sangtec 100 [S-100ß] and LIA-mat NSE and Prolifigen [NSE], Sangtec Medical AB, Bromma, Sweden). Visibly hemolyzed samples were not analyzed for NSE because hemolysis elevates NSE levels. ${ }^{26}$ Detection limits for S-100 $\beta$ and NSE were $0.1 \mu \mathrm{g} / \mathrm{L}$ and $0.5 \mathrm{ng} / \mathrm{L}$, respectively. In cases in which $\mathrm{S}-100 \beta$ levels were under the detection level, S-100 $\beta$ values were set at $0.1 \mu \mathrm{g} / \mathrm{L}$.

In addition to the aforementioned protocol, venous blood was drawn serially during the first 24 hours after the operation (at 3, 6, 12, and 24 hours) in 10 patients to evaluate potential short-term changes in S-100 $\beta$ and NSE serum levels.
Surgical procedure. Midazolam and fentanyl dihydrogencitrate were used for anesthesia induction, pancuronium as a muscle relaxant, and isoflurane as an inhalation anesthetic. Surgery was performed under normothermic bypass $\left(35^{\circ} \mathrm{C}-37^{\circ} \mathrm{C}\right)$ with membrane oxygenators (COBE CML Duo, COBE Cardiovascular Inc, Denver, Colo, and Dideco D 703 Compactflo, Dideco, Mirandola, Italy) with the tubing system including an arterial line filter (COBE $40 \mu$ ). A nonpulsatile blood flow pump was used (Stoeckert S3, Stoeckert, Germany). Temperature was measured intranasally, as well as in the pulmonary vein and in the arterial and venous lines of the extracorporeal system. Alpha-stat was used for $\mathrm{pH}$ maintenance.

Statistical analysis. Normally distributed data were expressed as mean \pm standard deviation and compared with a 2 -sample $t$ test or 1-way analysis of variance; non-normally distributed data were expressed as median and 95\% confidence intervals (CI) and were compared by the MannWhitney $U$, Kruskal-Wallis, or Wilcoxon tests as appropriate. Correlations of nonparametric data were examined by means of the Spearmann rank test; the $\chi^{2}$ test was used for comparison of frequencies. Relation between S-100 $\beta$ and NSE levels and operative parameters (duration of $\mathrm{CPB}$, reperfusion, and total operation time) was assessed by means of linear regression analysis. Receiver-operating characteristics (ROC) curves ${ }^{27}$ were used to evaluate the optimal cutoff values of S$100 \beta$ and NSE in predicting postoperative neurologic deficit.

Multivariable logistic regression analysis was performed to evaluate the value of relevant risk factors and $S-100 \beta$ and NSE levels for predicting postoperative adverse neurologic outcomes. The following factors were included in this analysis: age; sex; presence of hypertension, diabetes mellitus, peripheral vascular disease, or carotid disease; history of previous stroke or previous cardiac surgery; left ventricular ejection fraction; duration of bypass, reperfusion, and total operation time; and serum levels of S-100 $\beta$ and NSE on the first postoperative day. Concerning S-100 $\beta$ and NSE, the cutoff values evaluated through ROC curves were used in this analysis. Thus the odds ratio for adverse neurologic outcomes when S-100 $\beta$ and/or NSE exceeded a certain value were evaluated. Initial analysis was performed, including all potentially relevant factors, with a probability limit of $10 \%$ $(P<.1)$. Subsequently, parameters failing to reach significance were excluded by means of conditional backward selection, and the odds ratios for remaining parameters were recalculated. Two models were used: model 1 evaluated the predictive value of relevant parameters in distinguishing between type I and type II/III outcomes and model 2 between type I/II and type III outcomes. Additionally, a separate logistic regression model was calculated; this model evaluated the probability of adverse neurologic outcome (type II or III outcome) depending on the S-100 $\beta$ serum levels on the first postoperative day and relevant risk factors as evaluated in the initial multilinear regression analysis. S$100 \beta$ values were not dichotomized but rather retained as continuous values for the purposes of this model. Bonferroni correction was applied where appropriate. 
Table I. Prevalence of hypertension, diabetes mellitus, peripheral artery disease, and carotid artery disease and duration of bypass, reperfusion, and total duration of operative procedure depending on postoperative outcome

\begin{tabular}{|c|c|c|c|c|c|c|c|}
\hline & Type I & $P 1$ & Type II & $P 2$ & Type III & $P 3$ & $P$ \\
\hline $\mathrm{N}$ & 154 & & 26 & & 10 & & \\
\hline $\operatorname{Age}(y)^{*}$ & $62 \pm 8$ & $.02 \ddagger$ & $67 \pm 8$ & $1.00^{\ddagger}$ & $69 \pm 11$ & $.05^{\ddagger}$ & $.05^{\S}$ \\
\hline Hypertension & $62(40 \%)$ & $.98^{\prime \prime}$ & $11(42 \%)$ & $.56^{\| 1}$ & $6(60 \%)$ & $.37^{\| \prime}$ & $.47^{\prime \prime}$ \\
\hline $\operatorname{LVEF}(\%)^{*}$ & $62 \pm 1$ & $.38^{\ddagger}$ & $56 \pm 4$ & $.87^{\ddagger}$ & $50 \pm 3$ & $.07 \ddagger$ & $.03^{\S}$ \\
\hline History of cardiac surgery & $4(3 \%)$ & $.72^{\| 1}$ & $1(4 \%)$ & $.49^{\prime \prime}$ & $1(10 \%)$ & $.22^{\| \prime}$ & $.47^{\| \prime}$ \\
\hline Diabetes & $49(32 \%)$ & $.03^{\| \prime}$ & $14(54 \%)$ & $.46^{\| \prime}$ & $4(40 \%)$ & $.59^{\|}$ & $.10^{\| \prime}$ \\
\hline Peripheral artery disease & $30(19 \%)$ & $.16^{\| \prime}$ & $2(8 \%)$ & $.31^{11}$ & $2(20 \%)$ & $.97^{\prime \prime}$ & $.37^{\prime \prime}$ \\
\hline Carotid disease & $17(11 \%)$ & $.61^{\prime \prime}$ & $2(8 \%)$ & $.82^{\| \prime}$ & $1(10 \%)$ & $.92^{\|}$ & $.86^{\| \prime}$ \\
\hline History of stroke & $3(2 \%)$ & $.02^{\| \prime}$ & $4(15 \%)$ & $.68^{\| \prime}$ & $1(10 \%)$ & $.59^{\|}$ & $.004^{\|}$ \\
\hline Bypass (min) ${ }^{\dagger}$ & $95[90-100]$ & $.0001^{\mathrm{II}}$ & 148 [118-185] & $.22^{\mathbb{I}}$ & 139 [100-264] & $.01^{\mathrm{II}}$ & $.0001^{\#}$ \\
\hline Reperfusion $(\min )^{\dagger}$ & $33[31-36]$ & $.001^{\mathrm{II}}$ & $51[40-72]$ & $.10^{\mathrm{I}}$ & 49 [38-133] & $.005^{\mathbb{I}}$ & $.0001^{\#}$ \\
\hline Total OP $(\mathrm{min})^{\dagger}$ & $193[185-201]$ & $.0001^{\mathbb{I I}}$ & 270 [225-345] & $.41^{\mathrm{II}}$ & 257 [197-361] & $.02^{\mathbb{I}}$ & $.03^{\#}$ \\
\hline
\end{tabular}

Carotid disease, Unilateral or bilateral stenosis of the internal carotid artery $>50 \% ; L V E F$, left ventricular ejection fraction as assessed before the operation; Total $O P$, total operation time.

"Data expressed as mean \pm standard deviation.

'Data expressed as median and 95\% confidence intervals. $P 1$, Type I versus type II; $P 2$, type II versus type III; $P 3$, type III versus type I $\left({ }^{\ddagger} 2\right.$-sample $t$ test, ${ }^{\mathbb{T}}$ MannWhitney test, and " $\chi^{2}$ test); $P$ group comparison using 1 -way analysis of variance ${ }^{\S}$ and Kruskal-Wallis tests."

Table II. Duration of bypass, reperfusion, total duration of operative procedure, and prevalence of adverse neurologic outcomes depending on procedure type in 190 patients undergoing cardiac surgery

\begin{tabular}{|c|c|c|c|c|c|c|c|}
\hline & $C A B G$ & $P 1$ & $V R$ & $P 2$ & $C A B G / V R$ & $P 3$ & $P$ \\
\hline $\mathrm{N}$ & 147 & & 29 & & 14 & & \\
\hline $\operatorname{Age}(y)^{*}$ & $64 \pm 8$ & $.05^{\ddagger}$ & $59 \pm 11$ & $.001^{\frac{1}{2}}$ & $68 \pm 5$ & $.01^{\ddagger}$ & $.005^{\S}$ \\
\hline $\mathrm{CPB}(\min )^{\dagger}$ & 96 [91-101] & $.20^{\prime \prime}$ & $103[94-113]$ & $.0001^{\|}$ & 154 [134-176] & $.0001^{\|}$ & $.0001^{\mathrm{II}}$ \\
\hline Reperfusion $(\mathrm{min})^{\dagger}$ & 36 [34-39] & $.03^{\prime \prime}$ & $30[26-36]$ & $.001^{\|}$ & $49[40-60]$ & $.005^{11}$ & $.001^{\mathbb{I}}$ \\
\hline Total OP $(\min )^{\dagger}$ & 198 [190-208] & $.92^{\prime \prime}$ & 195 [180-219] & $.005^{\| \prime}$ & 265 [223-295] & $.001^{\prime \prime}$ & $.003^{\pi}$ \\
\hline Type II & 19 & $.55^{\#}$ & 2 & $.02^{\#}$ & 5 & $.02^{\#}$ & $.05^{\#}$ \\
\hline Type III & 4 & $.01^{\#}$ & 2 & $.02^{\#}$ & 4 & $.002^{\#}$ & $.001^{\#}$ \\
\hline $\mathrm{S}-100 \beta 1$ postop $(\mu \mathrm{g} / \mathrm{L})^{\dagger}$ & $0.4[0.3-0.5]$ & $.42^{\prime \prime}$ & $0.3[0.2-0.5]$ & $.0002^{\| 1}$ & $1[0.6-2.6]$ & $.0005^{11}$ & $.0001^{\mathrm{II}}$ \\
\hline NSE 1 postop $(\mathrm{ng} / \mathrm{L})^{\dagger}$ & $13.2[12.3-14.1]$ & $.005^{\| \prime}$ & 16.5 [14.3-18.9] & $.01^{\|}$ & $25.6[19.5-32]$ & $.0001^{\|}$ & $.0001^{\mathrm{II}}$ \\
\hline $\mathrm{S}-100 \beta 2$ postop $(\mu \mathrm{g} / \mathrm{L})^{\dagger}$ & $0.3[0.2-0.3]$ & $.68^{\prime \prime}$ & $0.3[0.2-0.4]$ & $.005^{\| \prime}$ & $0.7[0.5-1.8]$ & $.0002^{11}$ & $.001^{\mathbb{I}}$ \\
\hline NSE 2 postop $(\mathrm{ng} / \mathrm{L})^{\dagger}$ & $10.7[9.9-11.6]$ & $.002^{\prime \prime}$ & $14.8[11.8-17.4]$ & $\mathrm{NS}^{\|}$ & $19.6[15.8-25.3]$ & $.0001^{\|}$ & $.0001^{\text {II }}$ \\
\hline
\end{tabular}

$C A B G$, Coronary artery bypass grafting; $V R$, valve replacement; $C A B G / V R$, coronary artery bypass and valve replacement; $C P B$, cardiopulmonary bypass; $T o t a l ~ O P$, total duration of operative procedure.

"Data expressed as mean \pm standard deviation.

'Data expressed as median and 95\% confidence intervals. $P 1$, CABG versus VR; $P 2$, VR versus CABG/VR; $P 3$, CABG versus CABG/VR ( ${ }^{\ddagger} 2$-sample $t$ test, "MannWhitney test, and ${ }^{\#} \chi^{2}$ test); $P$ group comparison using 1-way analysis of variance ${ }^{\S}$ and Kruskal-Wallis tests ${ }^{\text {II }) .}$

\section{Results}

Patient characteristics. Prevalence of relevant risk factors is listed in Table I. Carotid disease was mild in 10 , moderate in 4 , and severe in further 4 patients, and a carotid occlusion was diagnosed in 2 patients. Eight patients had had a stroke between 6 months and 5 years before admission; this was ischemic in 7 and hemorrhagic in 1 patient. Multiple ischemic strokes had occurred in 2 patients.

Seven, 59, 72, and 9 patients underwent CABG for 1 , 2,3 , or 4 grafts, respectively. The aortic valve was replaced in 24, the mitral in 4, and both valves in 1 patient. In the group undergoing both procedures, the aortic valve was replaced in 10 patients $(1$ graft, $\mathrm{n}=5$; 2 grafts, $\mathrm{n}=3 ; 3$ grafts, $\mathrm{n}=2$ ), the mitral in 2 ( 2 grafts in both cases), and both valves in 2 patients ( 1 and 2 grafts). Patients undergoing both CABG and valve replacement were significantly older than the remaining patients. Additionally, patients undergoing CABG were older than those undergoing valve replacement (Table II). Total duration of the operative procedure was significantly longer in patients undergoing both CABG and valve replacement, followed by those solely undergoing CABG or valve replacement. The same was true for duration of $\mathrm{CPB}$ and reperfusion (Table II). 


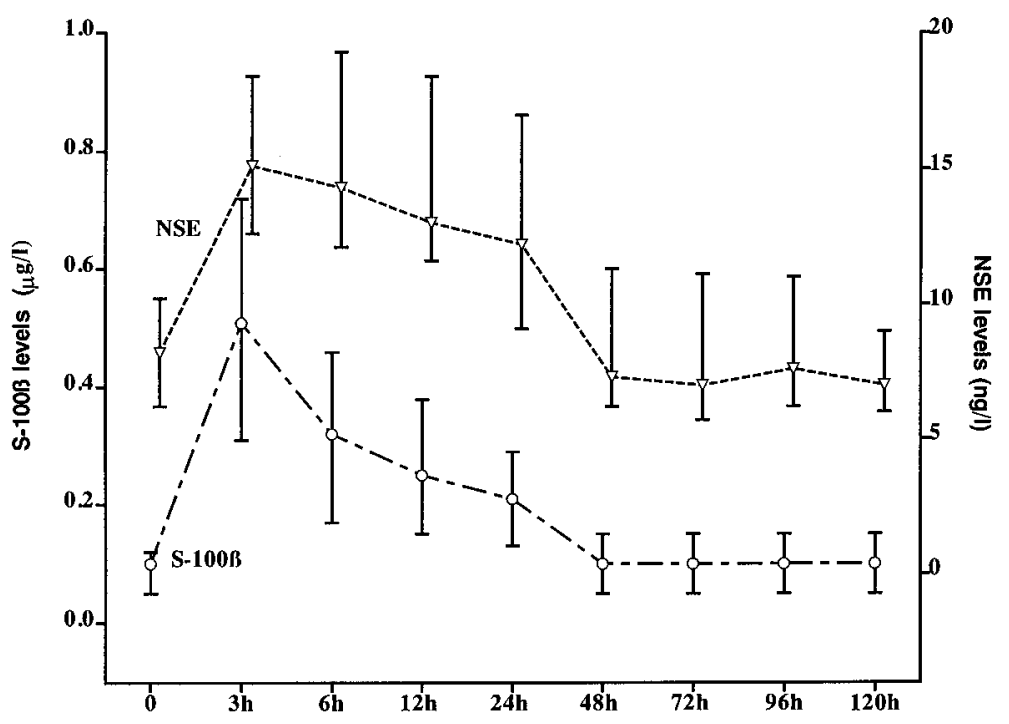

Fig 1. Time course of S-100 $\beta$ and NSE levels at 3, 6, and 12 hours and in the first 5 postoperative days in 10 patients with uncomplicated postoperative outcome. Data are expressed as median, and error bars represent $95 \%$ confidence intervals.

Outcome. Type II and III outcomes were observed in $26(13.7 \%)$ and $10(5.3 \%)$ patients, respectively. Significant differences in the incidence of neurologic complications in relation to the different operative procedures were noted (Table II). Disorientation, confusion, and agitation were the main symptoms in patients with type II outcomes; epileptic seizures were observed in 1 patient and myoclonic seizures in 2 patients. Symptoms subsided $4 \pm 0.5$ days after the operation (minimum 2 days, maximum 15 days) in all but 1 patient, in whom psychiatric referral was necessary. This patient was discharged 8 weeks later without any residual deficit. CCT scans were performed in 7 patients with type II outcomes on the second $(\mathrm{n}=5)$ or third (n $=2$ ) postoperative day and revealed marked subcortical atrophy in 5 and normal findings in 2 patients.

Five of the 10 patients with a type III outcome died. The cause of death was neurologic in 3 patients (brain swelling through ischemic infarction in all cases), multiple organ failure in 1, and cardiogenic shock in a further patient, who died on the second postoperative day. Creatinine levels were within normal range $(<100$ $\mu \mathrm{mol} / \mathrm{L})$ in 5 of the 10 patients with a type III outcome, whereas mild or moderate elevations were evident in the remaining patients (maximum values of 277, 238, 219,181 , and $137 \mu \mathrm{mol} / \mathrm{L}$ on the third, fourth, second, first, and second postoperative days, respectively). Deficit on discharge was mild in 2 patients (ataxia and discrete weakness of the right arm in 1 patient and discrete hemiparesis with complete functional indepen- dence in the other), moderate in 2 (moderate hemiparesis needing help for daily activities), and severe in 1 patient (severe hemiparesis, completely dependent).

CCT scans revealed multiple territory infarcts in 5 patients (bilateral middle cerebral artery, $\mathrm{n}=1$; middle and anterior cerebral arteries, $\mathrm{n}=2$; bilateral posterior cerebral artery, $\mathrm{n}=1$; middle and posterior cerebral arteries, $\mathrm{n}=1$ ) and single territory infarcts in 3 patients with type III outcomes (complete territory of the middle cerebral artery, $\mathrm{n}=1$; incomplete territory of the middle cerebral artery, $\mathrm{n}=2$ ). Repeat CCT scans were performed 2 to 4 days later in all patients and confirmed the initial findings. CCT of 1 patient with moderate hemiparesis disclosed no pathologic findings on the second postoperative day, and the test was not repeated. No CCT scan was performed in the patient who died on the second postoperative day. Infarction of the complete middle and anterior cerebral arterial territory was evident on necropsy. No watershed infarcts were diagnosed in any case.

S-100 $\beta$ and NSE. A total of 12 scheduled samples $(1 \%)$ were not obtained, and a further 25 NSE samples (2.1\%) were discarded because of hemolysis. Elevations in the serum levels of both proteins were observed in 9 of 10 patients in whom blood was serially drawn during the first 24 postoperative hours. These reached statistical significance 3 hours after the operation and remained significantly elevated until the second postoperative day (Fig 1). Outcome was uncomplicated in all 10 patients. 

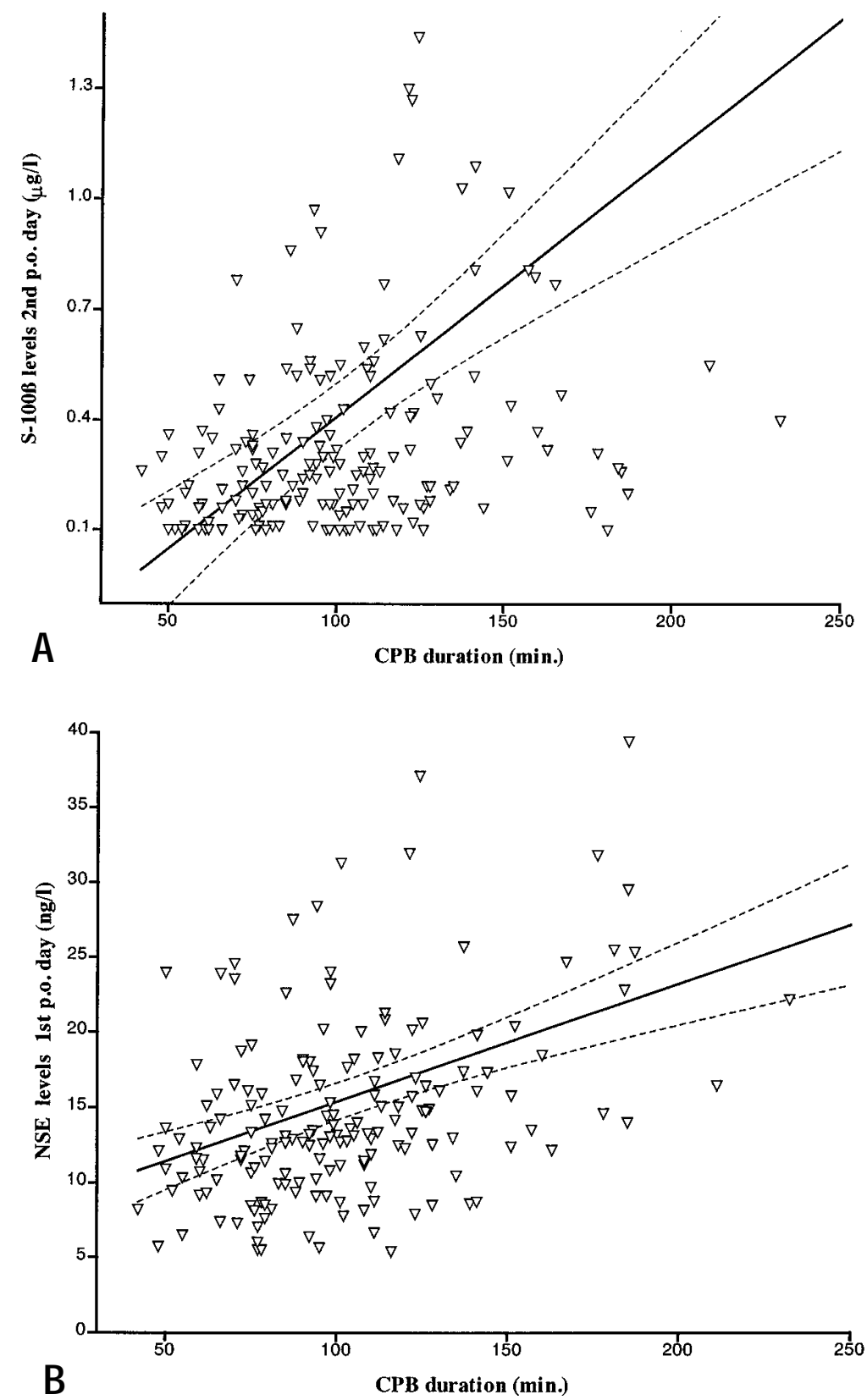

Fig 2. A, Linear regression between CPB duration and S-100ß levels in 190 patients undergoing cardiac surgery. Interrupted lines represent $95 \%$ confidence intervals. $r 2$ was 0.16 and Sy.x 0.62 . The equation best matching the data was $\mathrm{S}-100 \beta(\mu \mathrm{g} / \mathrm{L})=-0.3+0.007 \times \mathrm{CPB}$ duration (minutes). B, Linear regression between CPB duration and NSE levels in the first postoperative day in 190 patients undergoing cardiac surgery. Interrupted lines represent $95 \%$ confidence intervals. $r 2$ was 0.16 and Sy.x 8 . The equation best matching the data was NSE $(\mathrm{ng} / \mathrm{L})=$ $7.4+0.08 \times \mathrm{CPB}$ duration.

Serum S-100 $\beta$ and NSE levels were significantly higher in patients undergoing both CABG and valve replacement than in the remaining patients throughout the postoperative period. No significant differences were evident when comparing patients undergoing
CABG and those undergoing surgery for valve replacement (Table II).

Linear regression analysis revealed a significant relation between CPB duration and S-100 $\beta$ and NSE levels, reaching its highest values for $S-100 \beta$ on the sec- 

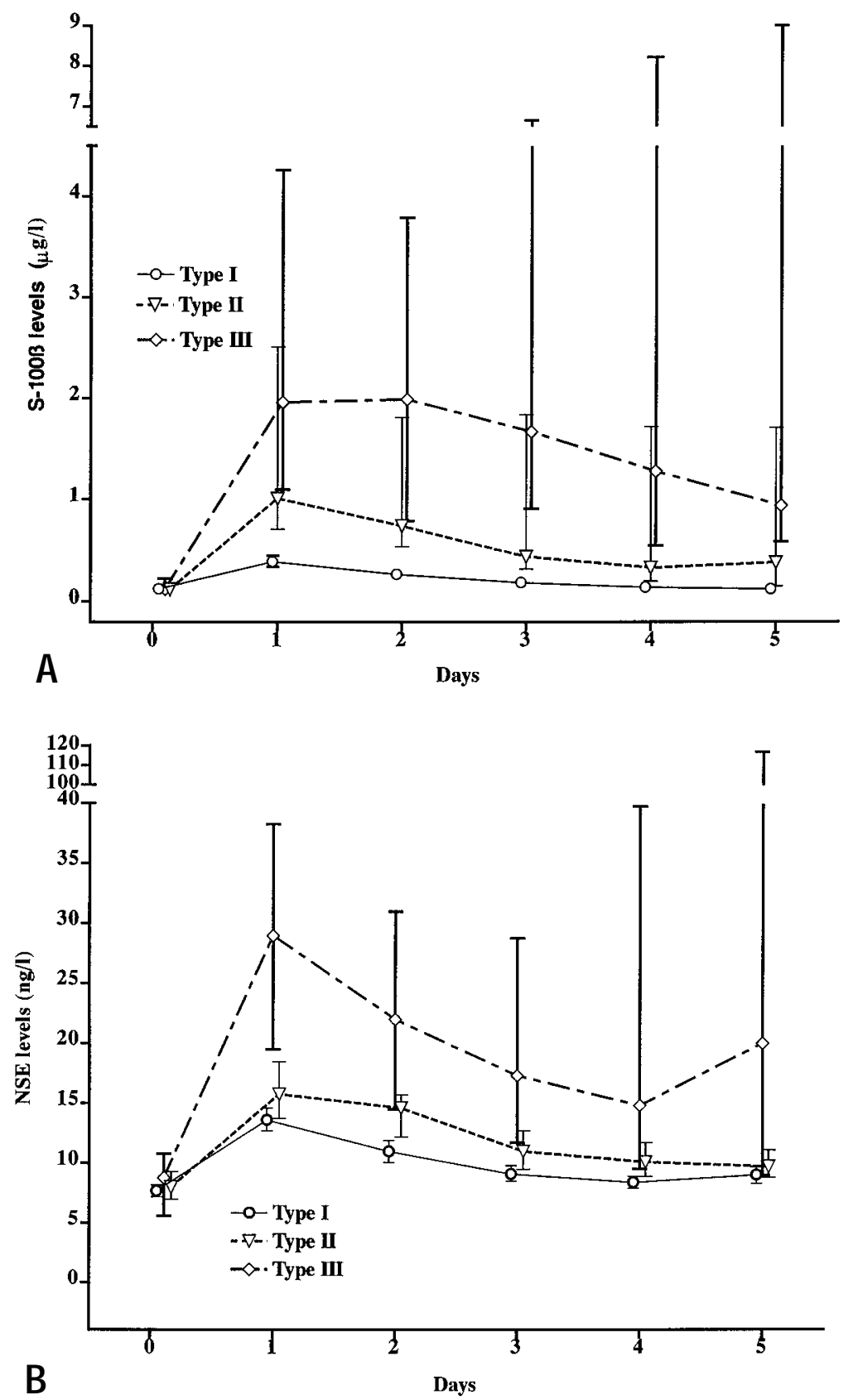

Fig 3. A, Time course of S-100 $\beta$ levels preoperatively (day 0) and in the first 5 postoperative days in neurologically asymptomatic patients (type I outcome), patients with postoperative confusion, agitation, and disorientation (type II outcome), and patients with postoperative stroke, stupor, or coma (type III outcome). Data are expressed as median, and error bars represent $95 \%$ confidence intervals. B, Time course of NSE levels preoperatively (day 0 ) and in the first 5 postoperative days in neurologically asymptomatic patients (type I outcome), patients with postoperative confusion, agitation, and disorientation (type II outcome), and patients with postoperative stroke, stupor, or coma (type III outcome). Data are expressed as median, and error bars represent $95 \%$ confidence intervals.

ond postoperative day $(r=0.41, P<.0001)$ and for NSE on the first postoperative day $(r=0.40, P<.0001)$ (Fig 2, $A$ and $B$ ).

Preoperative median S-100 $\beta$ and NSE levels were 0.12 $\mu \mathrm{g} / \mathrm{L}(95 \%$ CI $0.11-0.13 \mu \mathrm{g} / \mathrm{L})$ and $7 \mathrm{ng} / \mathrm{L}$ (95\% CI 6.4$7.7 \mathrm{ng} / \mathrm{L})$, respectively. A significant increase in the median serum levels of both proteins was observed in all patients on the first postoperative day (S-100ß: 0.12 

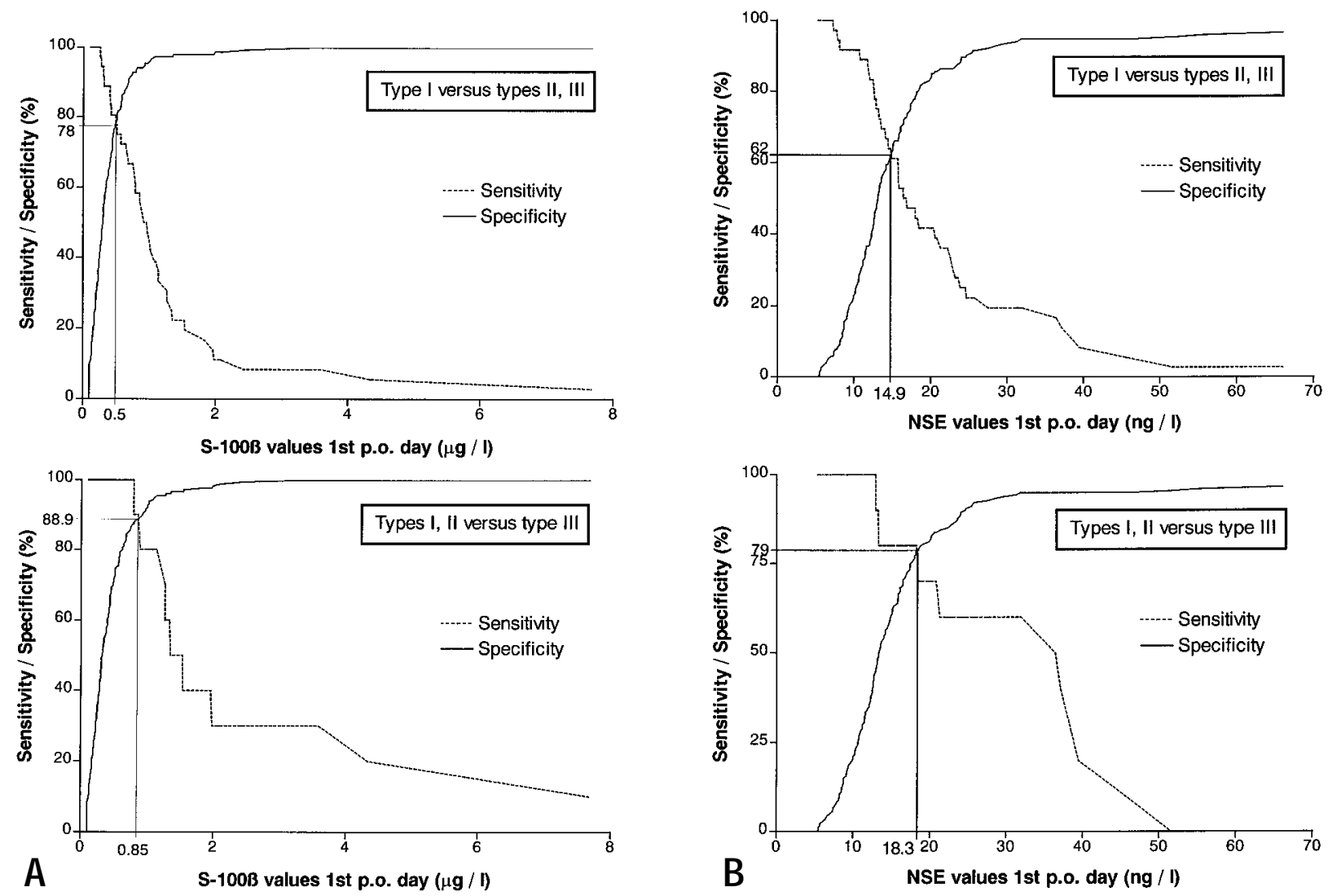

Fig 4. ROC curves for evaluation of the optimal cutoff values of A, S-100 $\beta$ and $\mathbf{B}$, NSE in the differentiation between patients with an uncomplicated outcome (type I) and those with type II or type III outcomes (upper curve) and between patients with types I/II and those with type III outcomes (lower curve). Optimal cutoff values and derived specificity and sensitivity are displayed.

$\mu \mathrm{g} / \mathrm{L}[95 \%$ CI $0.11-0.13 \mu \mathrm{g} / \mathrm{L}]$ vs $0.42 \mu \mathrm{g} / \mathrm{L}[95 \%$ CI $0.37-0.48 \mu \mathrm{g} / \mathrm{L}]$; NSE: $7.4 \mathrm{ng} / \mathrm{L}[95 \%$ CI $7-9 \mathrm{ng} / \mathrm{L}]$ vs $14.4 \mathrm{ng} / \mathrm{L}[95 \%$ CI $13.5-15.4 \mathrm{ng} / \mathrm{L}]$; both $P<.00001$, Mann-Whitney). In patients with an uncomplicated outcome, the increase of S-100 $\beta$ levels lost significance on the fourth postoperative day; NSE levels remained significantly elevated throughout the postoperative period. In patients with type II/III outcomes, S-100 $\beta$ and NSE levels were significantly higher than those in patients with a type I outcome and than preoperative values throughout the postoperative period (Fig 3, $A$ and $B$ ). Levels of both proteins were significantly higher in association with type III as compared with type II outcomes; this difference was statistically significant throughout the postoperative period, with the exception of NSE levels on the fourth postoperative day (Fig 3, $A$ and $B$ ).

Within the group of patients with type III outcomes, peak values for S-100 $\beta$ and NSE were higher in the patients who died than in those who survived (S-100 $\beta$ $3.4 \mu \mathrm{g} / \mathrm{L}$ [95\% CI $2-20 \mu \mathrm{g} / \mathrm{L}$ ] vs $1.4 \mu \mathrm{g} / \mathrm{L}$ [95\% CI 0.6-
$4.3 \mu \mathrm{g} / \mathrm{L}$ ]; NSE: $31 \mathrm{ng} / \mathrm{L}$ [95\% CI 17-40 ng/L] vs 28 $\mathrm{ng} / \mathrm{L}[95 \% \mathrm{CI} 13-46 \mathrm{ng} / \mathrm{L}] ; P=.07$ and .75 , MannWhitney test).

The optimal cutoff values of S-100 $\beta$ and NSE for predicting adverse neurologic outcomes were evaluated by means of ROC curves (Fig 4, $A$ and $B$ ). Both NSE and S-100 $\beta$ levels demonstrated high sensitivity and specificity in identifying patients with type III outcomes. Identification of all patients with adverse outcomes (types II and III) was also feasible, sensitivity and specificity of S-100 $\beta$ levels being markedly higher than those obtained with the use of NSE levels. On the other hand, S- $100 \beta$ levels below $1.1 \mu \mathrm{g} / \mathrm{L}$ on the first postoperative day had a specificity of $97.4 \%$ in excluding adverse neurologic outcomes. Similar results were obtained regarding NSE levels on the first postoperative day ( $86 \%$ of patients with a type I outcome had NSE levels < $20 \mathrm{ng} / \mathrm{L}$ ).

The first multivariable linear regression model identified bypass duration, left ventricular ejection fraction, 
Table III. Evaluation of independent predictors of adverse neurologic outcomes by means of multiple logistic regression analysis with backward selection procedure in 190 patients undergoing cardiac surgery

\begin{tabular}{lccc}
\hline Variables & Odds ratio & $95 \%$ CI & Probability \\
\hline LVEF $(\%)$ & 0.97 & $0.94-1$ & .07 \\
Bypass duration $(\mathrm{min})$ & 1.02 & $1-1.04$ & .006 \\
$\mathrm{~S}-100 \beta \leq 0.5 ; \mathrm{NSE} \leq 14.4^{*}$ & 1 & & \\
$\mathrm{~S}-100 \beta \leq 0.5 ; \mathrm{NSE}>14.4^{*}$ & 1.56 & $0.29-8.28$ & .6 \\
$\mathrm{~S}-100 \beta>0.5 ; \mathrm{NSE} \leq 14.4^{*}$ & 16.22 & $3.43-76.65$ & .0004 \\
$\mathrm{NSE}>14.4 ; \mathrm{S}-100 \beta>0.5^{*}$ & 21.79 & $5-95.06$ & .00001 \\
\hline
\end{tabular}

$L V E F$, Left ventricular ejection fraction.

"NSE values in nanograms per liter; S-100 $\beta$ values in micrograms per liter; all values were evaluated on the first postoperative day.

increase of $S-100 \beta$ values $>0.5$, and combined increase of S-100 $\beta$ values $>0.5$ and NSE values $>14.4$ as significant predictors for type II or type III outcomes. The model was then recalculated with the use of only these parameters. The results are listed in Table III. Similar results were obtained when the model was recalculated, including only patients undergoing CABG. It must be noted that the observed lack of influence of previous stroke or cardiac surgery could be due to the low number of patients (Table I).

The second multivariable linear regression model could not be calculated because of the low number of type III outcomes. Univariate analysis demonstrated a high predictive value for both $\mathrm{S}-100 \beta>0.85 \mu \mathrm{g} / \mathrm{L}$ (odds ratio 68.14, 95\% CI 8.2-565.16, $P<.0001$ ) and NSE > $18.3 \mathrm{ng} / \mathrm{L}$ (odds ratio $7.3,95 \%$ CI 1.59-33.44, $P$ $<.01)$. Because of the low number of cases, no adjustment for bypass duration or left ventricular ejection fraction was performed in these cases.

The formula derived by the third multivariable linear regression model was as follows:

Probability $=1 /(1 /[\exp (3.67 \times \mathrm{S}-100 \beta[\mu \mathrm{g} / \mathrm{L}]+$ $0.021 \times$ bypass duration [min] -

$0.0239 \times \operatorname{LVEF}[\%]-4.538)])$

whereby mean bypass duration was calculated as 105.93 minutes and mean left ventricular ejection fraction (LVEF) as $60.49 \%$. S- $100 \beta$ values $>1.4 \mu \mathrm{g} / \mathrm{L}$ were related to an $80 \%$ probability of adverse neurologic outcome; this reached $90 \%$ when S-100 $\beta$ levels exceeded $1.7 \mu \mathrm{g} / \mathrm{L}$ (Fig 5).

\section{Discussion}

A basic methodologic difference between the present study and previous reports is the choice of sampling period. We assumed that elevated S-100 $\beta$ and NSE levels in the early postoperative hours would not provide

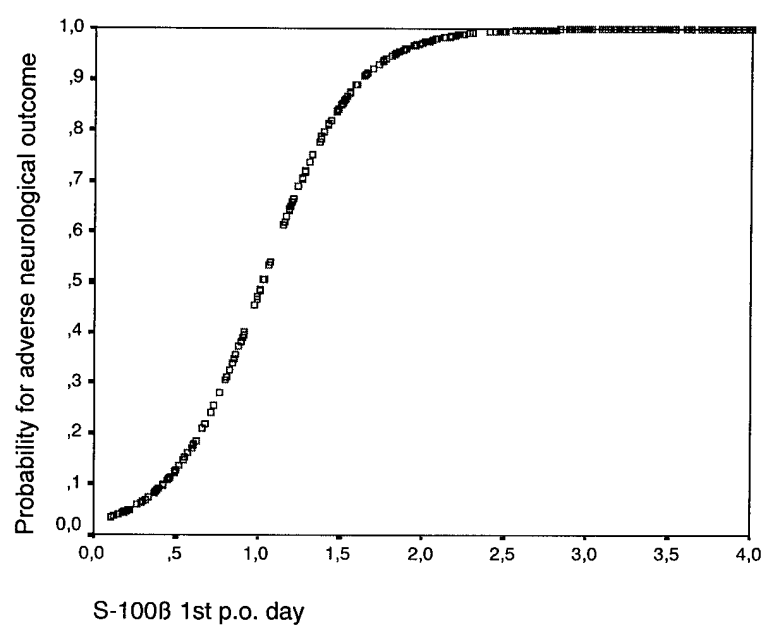

Fig 5. Probability for adverse neurologic outcome (types II and III) depending on S-100 $\beta$ values on the first postoperative day, calculated by means of a logistic regression model.

relevant prognostic information concerning neurologic deficit; therefore we performed the first postoperative blood sampling 24 hours after the operation, instead of acquiring blood samples during the operation as well as within the first 4 to 24 postoperative hours, as was the case in most recent studies. The significantly elevated S-100 $\beta$ and NSE serum levels in the first 24 postoperative hours observed in 9 of the 10 patients with an uncomplicated outcome (Fig 1) in this study support this assumption. Identical results were reported by Taggart and associates ${ }^{21}$ : Elevated S-100 $\beta$ serum levels were found in 21 of 43 patients 4 hours after skin closure; none of these patients had neurologic symptoms. Furthermore, both S-100 $\beta$ and NSE were reported to reach their peak increase 2 to 3 days after middle cerebral artery occlusion in an animal mode ${ }^{28}$ and after ischemic stroke in patient studies, ${ }^{14-17}$ adding weight to our methodologic approach.

The high specificity and sensitivity of S-100 $\beta$ serum levels in predicting adverse neurologic outcome is a major finding of the present study. Our results suggest that $\mathrm{S}-100 \beta$ levels 24 hours after the operation possess a sensitivity and specificity of approximately $90 \%$ in identifying patients with cerebral lesions, thus indicating the need for further examinations. The opposite statement was also found to be true, as specificity of S$100 \beta$ levels in excluding cerebral lesions was $97 \%$. Additionally, the applied multivariable logistic regression model demonstrated that $S-100 \beta$ serum levels possess a high predictive value for prediction of adverse neurologic outcomes, independently of other relevant risk factors. Serums levels of NSE were shown to possess a lower predictive value; sole increase of NSE was 
not predictive of adverse neurologic outcomes, and increase of both S-100 $\beta$ and NSE levels only marginally improved the predictive value of a sole $S-100 \beta$ increase. The demonstrated superiority of $S-100 \beta$ in comparison with NSE levels is in agreement with most previous reports. We did not observe elevated NSE levels in the absence of elevated S-100 $\beta$ levels in any of the symptomatic patients; thus routine evaluation of both proteins appears redundant and not cost effective.

The significant postoperative elevation of S-100 $\beta$ and NSE serum levels irrespective of neurologic outcome suggests that cardiac surgery almost always results in brain injury. This remains unnoticed on clinical examination but can readily be detected by neuropsychologic testing. ${ }^{3-5}$ The close relation observed for duration of CPB with both elevation of S-100 $\beta$ and NSE levels and outcome identifies this procedure as responsible for at least part of the postoperative deficit.

Recent reports suggested a correlation between S$100 \beta$ levels and lesion size on CCT. ${ }^{14-16}$ The size of our study, as well as the low number of patients with focal neurologic lesions, prohibited such analysis. Interestingly, vascular encephalopathy was diagnosed in 5 of 7 patients with postoperative disorientation who underwent CCT. This finding is in accordance with the results of Schmidt and associates, ${ }^{29}$ who identified ventricular width as the only risk factor for postoperative encephalopathy. We hypothesize that the pre-existing encephalopathy in our patients was exacerbated through microembolism and/or hypoperfusion during $\mathrm{CPB}$, causing the aforementioned symptoms. We did not apply stroke scales to characterize functional outcome in our patients; this was due to the low number of patients in whom permanent deficit was observed.

We conclude that serum levels of S- $100 \beta$ sampled on the first postoperative day are valid clinical predictors for adverse neurologic outcome in patients undergoing cardiac surgery and might prove useful in assessing the effect of alternative surgical techniques or neuroprotective treatment.

\section{REFERENCES}

1. Libman RB, Wirkowski E, Neystat M, Barr W, Gelb S, Graver M. Stroke associated with cardiac surgery: determinants, timing, and stroke subtypes. Arch Neurol 1997;54:83-7.

2. Roach GW, Kanhuger M, Mangano CM, et al. Adverse cerebral outcomes after coronary bypass surgery. N Engl J Med 1996;335:1857-62.

3. Vingerhoets G, Van Nooten G, Vermassen F, De Soete G, Jannes C. Short-term and long-term neuropsychological consequences of cardiac surgery with extracorporeal circulation. Eur J Cardiothorac Surg 1997;11:424-31.

4. Treasure T, Smith PL, Newman S, et al. Impairment of cerebral function following cardiac and other major surgery. Eur $\mathbf{J}$ Cardiothorac Surg 1989;3:216-21.

5. Smith PL. The cerebral complications of coronary artery bypass surgery. Ann R Coll Surg Engl 1988;70:212-6.

6. Usui A, Kato K, Abe T, Murase M, Tanaka M, Takeuchi E. S100ao protein in blood and urine during open-heart surgery. Clin Chem 1989;35:1942-4.

7. Marangos PJ, Schmechel D, Parma AM, Clark RL, Goodwin FK. Measurement of neuron-specific (NSE) and non-neuronal (NNE) isoenzymes of enolase in rat, monkey and human nervous tissue. J Neurochem 1979;33:319-29.

8. Ross SA, Cunningham RT, Johnston CF, Rowlands BJ. Neuronspecific enolase as an aid to outcome prediction in head injury. $\mathrm{Br}$ J Neurosurg 1996;10:471-6.

9. Yamazaki Y, Yada K, Morii S, Kitahara T, Ohwada T. Diagnostic significance of serum neuron-specific enolase and myelin basic protein assay in patients with acute head injury. Surg Neurol 1995;43:267-70.

10. Missler U, Wandinger KP, Wiesmann M, Kaps M, Wessel K. Acute exacerbation of multiple sclerosis increases plasma levels of S-100 protein. Acta Neurol Scand 1997;96:142-4.

11. DeGiorgio CM, Correale JD, Gott PS, et al. Serum neuron-specific enolase in human status epilepticus. Neurology 1995;45:1134-7.

12. DeGiorgio CM, Gott PS, Rabinowicz AL, Heck CN, Smith TD, Correale JD. Neuron-specific enolase, a marker of acute neuronal injury, is increased in complex partial status epilepticus. Epilepsia 1996;37:606-9.

13. van de Pol M, Twijnstra A, ten Velde GP, Menheere PP. Neuronspecific enolase as a marker of brain metastasis in patients with small-cell lung carcinoma. J Neurooncol 1994;19:149-54.

14. Fassbender K, Schmidt R, Schreiner A, et al. Leakage of brainoriginated proteins in peripheral blood: temporal profile and diagnostic value in early ischemic stroke. J Neurol Sci 1997;148:101-5.

15. Missler U, Wiesmann M, Friedrich C, Kaps M. S-100 protein and neuron-specific enolase concentrations in blood as indicators of infarction volume and prognosis in acute ischemic stroke. Stroke 1997;28:1956-60.

16. Cunningham RT, Watt M, Winder J, et al. Serum neurone-specific enolase as an indicator of stroke volume. Eur J Clin Invest 1996;26:298-303.

17. Buttner T, Weyers S, Postert T, Sprengelmeyer R, Kuhn W. S-100 protein: serum marker of focal brain damage after ischemic territorial MCA infarction. Stroke 1997;28:1961-5.

18. Abraha HD, Butterworth RJ, Bath PM, Wassif WS, Garthwaite J, Sherwood RA. Serum S-100 protein, relationship to clinical outcome in acute stroke. Ann Clin Biochem 1997;34:366-70.

19. Fogel W, Krieger D, Veith M, et al. Serum neuron-specific enolase as early predictor of outcome after cardiac arrest. Crit Care Med 1997;25:1133-8.

20. Isgro F, Schmidt CH, Pohl P, Saggau W. A predictive parameter in patients with brain related complications after cardiac surgery? Eur J Cardiothorac Surg 1997;11:640-4.

21. Taggart DP, Bhattacharya K, Meston N, et al. Serum S-100 protein concentration after cardiac surgery: a randomised trial of arterial line filtration. Eur J Cardiothorac Surg 1997;11:645-9.

22. Taggart DP, Mazel JW, Bhattacharya K, et al. Comparison of serum S-100b levels during CABG and intracardiac operations. Ann Thorac Surg 1997;63:492-6.

23. Westaby S, Johnsson P, Parry AJ, et al. Serum S100 protein: a 
potential marker for cerebral events during cardiopulmonary bypass. Ann Thorac Surg 1996;61:88-92.

24. Johnsson P, Lundqvist C, Lindgren A, Ferencz I, Alling C, Stahl E. Cerebral complications after cardiac surgery assessed by $\mathrm{S}$ 100 and NSE levels in blood. J Cardiothorac Vasc Anesth 1995;9: 694-9.

25. Schaarschmidt H, Prange HW, Reiber H. Neuron-specific enolase concentrations in blood as a prognostic parameter in cerebrovascular diseases. Stroke 1994;25:558-65.

26. Gao F, Harris DN, Sapsed-Byrne S, Sharp S. Neurone-specific enolase and Sangtec 100 assays during cardiac surgery. Part III. Does haemolysis affect their accuracy? Perfusion 1997;12:171-7.

27. Swets JA, Pickett RM, Whitehead SF, et al. Assessment of diagnostic technologies. Science 1979;205:753-9.

28. Hardemark HG, Ericsson N, Kotwica Z, et al. S-100 protein and neuron-specific enolase in CSF after experimental traumatic or focal ischemic brain damage. J Neurosurg 1989;71:727-31.

29. Schmidt R, Fazekas F, Offenbacher H, et al. Brain magnetic resonance imaging in coronary artery bypass grafts: a pre- and postoperative assessment. Neurology 1993;43:775-8.

\section{Online-www.aats.org}

Now you can get The Journal of Thoracic and Cardiovascular Surgery online. The Journal online brings you faster delivery time, easy searching of current and back issues, links to PubMed, AATS, WTSA, and other important sites, and more. Visit the Journal online today.

\section{Receive tables of contents by e-mail}

To receive the tables of contents by e-mail, sign up through our Web site at http://www.mosby.com/jtcvs. Choose E-mail Notification. Simply type your e-mail address in the box and click the Subscription button.

Alternatively, you may send an e-mail message to majordomo@mosby.com. Leave the subject line blank and type the following as the body of your message: subscribe jtcvs_toc.

You will receive an e-mail to confirm that you have been added to the mailing list. Note that table of contents e-mails will be sent out when a new issue is posted to the Web. 